\title{
CORNELIA, CLODIA, HORTENSIA Y SULPICIA
}

\author{
RESEÑA DEL LIBRO: LAURA CAROLINA DURÁN. CORNELIA, CLODIA, HORTENSIA Y \\ SULPICIA. MUJERES DE LA TARDO-REPÚBLICA ROMANA. BUENOS AIRES: TESSEO \\ PRESS. 2021, 159 PP., ISBN 978-9878697284
}

\author{
Mariano Olivera \\ (Universidad Nacional de Mar del Plata) \\ filosofiayciencia2019@gmail.com
}

\section{CORNELIA, CLODIA, HORTENSIA Y SULPICIA \\ Mujeres de la tardo-república romana}

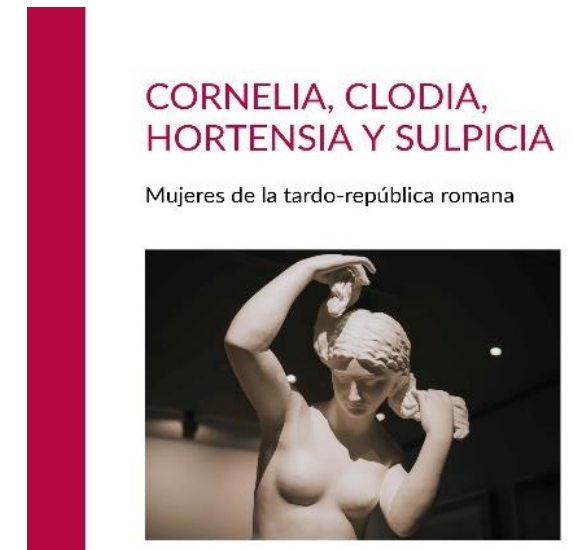

LAURA CAROLINA DURÁN
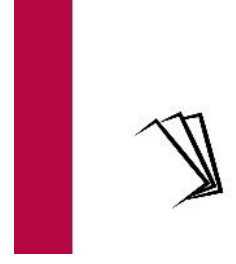

Recibido: $12 / 01 / 2022$

Aprobado: 16/01/2022

Cornelia, Clodia, Hortensia y Sulpicia de Laura Carolina Durán, es un libro que nos convoca a una lectura enriquecedora que testimonia y revive el lugar activo y participativo de la mujer en la historia del pensamiento y la política Occidental, particularmente en el período de la tardo-república romana (201-27 a.C). La autora nos invita a pensar lo invisibilizado, oculto, excluido y silenciado bajo los tradicionales estereotipos femeninos y las feminidades formadas, para ello se basa en un fidedigno ejercicio de recuperación, análisis y recopilación de materiales textuales que reflejan los testimonios, hechos y hazañas de cuatro mujeres excepcionales, cuyas improntas han legado un registro activo en la República Romana tardía.

En el prefacio de la obra, indica que su propuesta avanza contra la corriente de aquella concepción histórica que desconoce o sostiene la negación de las mujeres en el espacio sociopolítico y en la producción de pensamiento y cultura. En todo el estudio de la autora, subyace la intención y el desafío de responder a la pregunta sobre el lugar de la mujer en el pensamiento, la acción

y la palabra, condensado en uno de los periodos claves de construcción y determinación del pensamiento y de la institucionalidad occidental. Así realiza una contrahistoria androcéntrica, que nos muestra con detalle de citas, anécdotas y descripciones como irrumpen cuatro romanas con personalidades características y una posición social definida: matronas, mujeres de la elite romana.

El contenido del libro abarca 159 páginas y se estructura en Introducción, cuatro capítulos que abordan cada una de las cuatro mujeres intituladas y un Epílogo.

\section{Introducción}

En la introducción se caracteriza el lugar asignado, el modo de vida y el comportamiento esperado de las mujeres en el periodo elegido. Se titula "Roma. La domus, el lugar de las mujeres en la tardorepública". El eje central es la delimitación del espacio viril del femenino, en la dicotomía Foro-domus. El Foro, el centro de la vida política y jurídica es el ámbito masculino por excelencia, mientras que la mujer queda relegada al Domus (casa) y a la dependencia del pater familias (jefe o cabeza de familia) o 
dominus (señor), el cual ejercía patria potestas (patria potestad) sobre la vida y muerte de todos los miembros de su familia. A partir de aquí se sintetiza como se configura la feminidad en la subjetividad masculina romana, en la representación de los valores que debían moldearlas, la vituperación de los vicios que las caracterizaban, y las expectativas, proyectos, deseos y temores que se tenían para con ellas.

\section{Cornelia}

El primer capítulo nos habla elocuentemente de la vida y la familia de Cornelia, célebre no por haber sido madre, esposa e hija de importantes hombres de la República, sino por su activa y discreta intervención política destinada a conservarla de las fragmentaciones e intrigas dadas por la lucha del poder entre los hombres. Así se realiza una contrapropuesta biográfica a la mujer cuya fama orbita en torno al centro del universo masculino, rescatando en un apartado a la olvidada figura de su madre Emilia, la cual participo y fue responsable del resultado de un evento político que puede entenderse históricamente como la primera desobediencia al régimen patriarcal y manifestación de protesta femenina en las calles, el reclamo por la derogación de la lex Oppia sumptuaria, la cual establecía una restricción en público al uso de artículos de lujo.

Se señala entonces, la figura y el antecedente de su madre como matrona influyente, políticamente activa. Cornelia dignificara su herencia, intercediendo en conflictos armados en los que se hallan involucrados su prole y los cuales considera perjudiciales para la tardo-república, en un momento de turbulentas escaramuzas entre patricios y plebeyos. Se describe como actúa con determinación, como pacificadora y atenuante de las venganzas y las reformas propuestas por sus hijos, procurando evitar la catástrofe.

El apartado justifica como Cornelia se convierte convirtió en prototipo de madre y matrona romana admirada, hasta tal punto que se erigió una estatua en su honor.

\section{Clodia}

El segundo capítulo representa a Clodia, la antítesis de Cornelia como modelo de respetable matrona romana, ya que encarna todo lo opuesto a lo que la cultura romana espera y admira de la mujer domina. Incluso fue descalificada y difamada por Cicerón bajo el título de lujuriosa meretrix, ávida de venganza. Ya que se vio envuelta en controversias, por sus relaciones con varios hombres al quedar viuda. Precisamente se refiere a una historia de amor y traición entre Clodia y Celio, un discípulo de Cicerón el cual la matrona acuso de intento de envenenamiento, y que fue llevado al espacio de la defensa judicial. Este es un capítulo que encarna a la mujer que asume cierta libertad y a la denunciante que no se calla y recibe una carga abrumadora de vicios y valoraciones peyorativas. Se demuestra que la palabra de la mujer en el ámbito judicial resulta desvalorizada, aún más desde la posición de denunciante. Se trabaja con minuciosa exhaustividad el discurso de Cicerón que desacredita y degrada con saña y elocuencia a la persona de Clodia. También se expone con detalle la posible representación análoga de Clodia con Lesbia una meretriz, en la poesía de Catulo. Son diversas representaciones misóginas las que apuntan a Clodia, una mujer que sacudió el silencio sumiso y se desplazó con alguna libertad en relación a las habituales limitaciones impuestas. De allí tal vez lo que estimulo la dureza de las críticas de sus contemporáneos.

\section{Hortensia}

La tercera sección nos interpela con la figura de Hortensia, una mujer que domina el ámbito del discurso y que ejerce como oradora en defensa de un colectivo de mujeres. Se conserva un solo discurso de su autoría, el cual será sutilmente analizado en todo el capítulo, desde su procedencia histórica, hasta su valor retórico y político para el movimiento femenino. Hortensia toma la palabra en representación del grupo de matronas, que reclaman sus derechos, ya que ella puede abogar en contra de lo que se les ha 
impuesto, mejor que ninguno de los varones que no han osado defenderlas, mientras que otros intentan silenciarla.

La autora señala el ingenio de un discurso que persuade manteniendo el delicado equilibrio entre la promoción de una modificación en las normas del funcionamiento social y la aceptación de alguno de los imperativos del patriarcado. Pero también arremete con valentía al declarar que el ordo matrorum es obligada por los triunviros a impuestos y a la confiscación de sus bienes en pos de financiar una guerra que no esconde más que una guerra civil ilegítima, contra los republicanos. El discurso de Hortensia destaca por argumentaciones pacifistas y por sostener la independencia económica que deben tener las mujeres de su posición social, que no deben verse sometidas a pagar ni verse despojadas de sus bienes por contiendas espúreas, debidas a intereses de poder de los hombres.

\section{Sulpicia}

El último capítulo nomina a la poetisa Sulpicia, una mujer que concurrió en los espacios de producción y circulación de poesía y de los literatos, con una elaboración auténticamente femenina y de un valor que dista de aquellas interpretaciones que la han caracterizado como una figura menor, o una imitación de sus colegas masculinos. Dicho de otro modo, una poetisa que tuvo interés en tomar lugar con sus poemas en la escena pública androcentrada. La particularidad de Sulpicia reside en ser la primera escritora romana de quien se conservan textos poéticos y sobrevivir en el ámbito público. Por ello, se nos introduce en un apartado donde se las compara con poetisas romanas de las cuales no se han conservado obras, pero si referencias indirectas.

Aquí se analizan con detenimiento los epigramas de Sulpicia, con los cuales podemos disfrutar de un acercamiento a una experiencia poética que es expresión del deseo, la erótica y la identidad amatoria desde la perspectiva de una subjetividad femenina, que transmite un mundo distinto al de la voz de los poetas latinos masculinos.

\section{Epílogo}

La reflexión final de Durán apunta al ejemplo de estas cuatro mujeres que de un dominio delimitado y definido en el domus o vivienda, atraviesan las barreras confinatorias y amplían los límites de su propio status social, tomando la palabra e "invadiendo" el espacio categorizado en el signo de viril. Señala la importancia de nuestras protagonistas, matronas que implican una irrupción en la política y la sociedad romana, cuya participación tuvo un impacto valorable en la organización social y jurídica de la República, y que también arremeten contra los ideales y los estándares de género reivindicando el deseo femenino y la subversión de los roles asignados.

Así toda su investigación se define y da cierre en sus palabras de "Todas estas mujeres que pensaban, hablaban y escribían" (p. 134)

Para concluir nuestro recorrido, sostengo que esta obra nos ofrece un aporte indispensable en el proyecto de recuperación y reivindicación de la Memoria y la historia de la mujer, circunscripto con detalle a un período específico y provisto de profusas citas y referencias textuales. Una investigación completa y comprometida, para aquellos que se pregunten si la mujer ha tenido participación en la historia y el pensamiento de Occidente, adoptando como ejemplos dignos a cuatro mujeres romanas en un escenario avasallante, predominantemente masculino. Es en definitiva una historia del empoderamiento de la fémina, donde imperaba su silenciamiento público y su ocultamiento en sus hogares. Cuatro matronas empoderadas en situaciones adversas y subyugantes, en las que demostraron valentía y determinación, guiando o representando a colectivos de las mujeres. Mujeres valientes que actuaban y decidían bajo situaciones críticas, tomaban la palabra, plasmaban su conciencia en la escritura, actuaban y se manifestaban en contra de lo que consideraban injusto, expresando sus deseos y derechos. 